\section{How and how early can we predict a stroke patient's fate after thrombectomy?}

\author{
Peter B Sporns
}

\section{National Institutes of Health Stroke Scale 24 hours after thrombectomy predicts functional outcome of patients with stroke and may serve as early outcome parameter in future studies}

Early prediction of long-term functional outcome after acute ischaemic stroke is an appealing target as it may serve for early allocation of medical and financial resources and as early endpoint for future trials. Whereas in patients with ischaemic stroke after intravenous thrombolysis early surrogates such as neurological improvement of National Institutes of Health Stroke Scale (NIHSS) at 2 hours compared with admission NIHSS were described as reliable predictors of 3-month functional outcome, ${ }^{1}$ to date no consensus exists which parameters are suited as early surrogate of functional outcome after mechanical thrombectomy (MT).

Meyer et $a l^{2}$ present an analysis of the German Stroke Registry Endovascular Treatment including 2262 patients treated with MT at 25 comprehensive stroke centres. For this study, different early surrogate parameters based on the NIHSS were defined including NIHSS at admission and after 24 hours as well as NIHSS percentage change and NIHSS delta change from admission to 24 hours after thrombectomy. Interestingly, of these parameters NIHSS at 24 hours had the highest discriminative ability to predict excellent (defined as modified Rankin Scale Score, mRS 0-1) and favourable functional outcome (mRS $0-2$ ) at 3

Neuroradiology, Universitatsspital Basel, Basel, Switzerland

Correspondence to Dr Peter B Sporns,

Neuroradiology, Universitatsspital Basel, Basel 4031, Switzerland; peter.sporns@hotmail.de months independent of admission stroke severity. When using a binary definition with an 8-point NIHSS threshold at 24 hours, the authors report a sensitivity and specificity of $\sim 80 \%$, consequently identifying $70 \%$ of patients with favourable functional outcome. On the other hand, this means that $\sim 15 \%$ of patients with an NIHSS $\leq 8$ at 24 hours had poor neurological outcomes (defined as mRS 4-6). The authors explain this with the finding that the only independent predictor for reversion of the outcome prediction from NIHSS at 24 hours to 90 days was advanced age which might be attributed to the high rates of comorbidities such as poststroke pneumonia in this elderly subgroup. In contrast, studies describe the possibility of good functional outcome at 3 months even when patients did not present with early clinical improvement suggesting the possibility of a 'stunned brain' syndrome with delayed recovery. ${ }^{3}$

A particular strength of the study is the large patient cohort from a prospectively collected registry including data collected at multiple centres in clinical routine, therefore presenting a 'real-life' cohort, which are known to differ from randomised trials. ${ }^{4}$ A limitation of the study that the authors acknowledge themselves is that the mRS, which served as underlying gold standard, does not represent the whole quality of life status but rather focuses on motor recovery.

Thinking of future studies it is appealing to have early clinical surrogates for patients' functional outcomes, which are easier to acquire and may result in lower percentages of missing values. This study demonstrates that the NIHSS at 24 hours is a reliable surrogate for prediction of functional outcome in patients with ischaemic stroke after MT. Accounting for age could improve prognostication and identifies a subgroup of patients where determination of longer-term functional outcomes may still be without any alternative.

Contributors PS is responsible for the whole content.

Funding The authors have not declared a specific grant for this research from any funding agency in the public, commercial or not-for-profit sectors.

Competing interests None declared.

Patient consent for publication Not required.

Provenance and peer review Commissioned; internally peer reviewed.

(c) Author(s) (or their employer(s)) 2020. No commercial re-use. See rights and permissions. Published by BMJ.

\section{D) Check for updates}

To cite Sporns PB. J Neurol Neurosurg Psychiatry 2020;91:1032

Received 14 July 2020

Accepted 15 July 2020

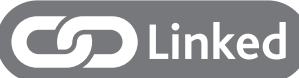

- http://dx.doi.org/10.1136/jnnp-2020-323742

J Neurol Neurosurg Psychiatry 2020;91:1032. doi:10.1136/jnnp-2020-324470

\section{REFERENCES}

1 Kharitonova T, Mikulik R, Roine RO, et al. Association of early National Institutes of health stroke scale improvement with vessel recanalization and functional outcome after intravenous thrombolysis in ischemic stroke. Stroke 2011;42:1638-43.

2 Meyer L, Broocks G, Bechstein M, et al. Early clinical surrogates for outcome prediction after stroke thrombectomy in daily clinical practice. J Neurol Neurosurg Psychiatry 2020;91:1055-9.

3 Alexandrov AV, Hall CE, Labiche LA, et al. Ischemic stunning of the brain: early recanalization without immediate clinical improvement in acute ischemic stroke. Stroke 2004;35:449-52.

4 Deb-Chatterji M, Pinnschmidt H, Flottmann F, et al. Stroke patients treated by thrombectomy in real life differ from cohorts of the clinical trials: a prospective observational study. BMC Neurol 2020;20:81. 